

\section{Why Can’t We All Just Get Along?}

ria. The human element is involved in obtaining, evaluating, and interpreting even the objective criteria and is subject to different measurements and interpretations. The element of variability of such measurements also (eg, breathing frequency, effort, heart rate, blood pressure) makes it nearly impossible to have a $100 \%$ agreement between clinicians. Interestingly, in a study on the pathophysiologic basis of acute respiratory distress in subjects failed an SBT, the authors found that $20 \%$ of subjects who failed had the same respiratory mechanics as those who were successful. ${ }^{10}$ Granted that new research, further clarity of definitions, and training may improve the clinicians' agreement regarding the SBT, ${ }^{8}$ it is unlikely, however, that the art and science of weaning will lead to a perfect agreement between clinicians, and it is likely that the conundrum will continue. It would be of interest to repeat the same study after a period of education and training to evaluate whether we have better agreement levels and if we are getting along better.

Ehab G Daoud MD

Division of Critical Care Medicine Kent Hospital

Warwick, Rhode Island

\section{REFERENCES}

1. MacIntyre N. Discontinuing mechanical ventilatory support. Chest 2007;132(3):1049-1056.
2. Meade M, Guyatt G, Cook D, Griffith L, Sinuff T, Kergl C, et al. Predicting success in weaning from mechanical ventilation. Chest 2001;120(6):400S-424S.

3. MacIntyre NR, Cook DJ, Ely EW Jr, Epstein SK, Fink JB, Heffner $\mathrm{JE}$, et al. Evidence-based guidelines for weaning and discontinuing ventilatory support. A collective task force facilitated by the American College of Chest Physicians, the American Association for Respiratory Care, and the American College of Crit Care Med Chest 2001;120(6):375S-395S.

4. Boles JM, Bion J, Connors A, Herridge M, Marsh B, Melot C, et al. Weaning from mechanical ventilation. Eur Respir J 2007;29(5): 10331056.

5. Sessler CN, Grossman CE. Getting to the CORE of weaning? Respir Care 2011;56(10):1621-1624.

6. Kollef MH, Shapiro SD, Silver P, St John RE, Prentice D, Sauer S, Ahrens TS, et al. A randomized, controlled trial of protocol-directed versus physician-directed weaning from mechanical ventilation. Crit Care Med 1997;25(4):567-574.

7. Ely EW, Baker AM, Dunagan DP, Burke HL, Smith AC, Kelly PT, et al. Effect on the duration of mechanical ventilation of identifying patients capable of breathing spontaneously. N Engl J Med 1996; 335(25):1864-1869.

8. Figueroa-Casas JB, Broukhim A, Vargas A, Milam L, Montoya R. Inter-observer agreement of spontaneous breathing trial outcome. Respir Care 2014;59(9):1324-1328.

9. Cappati KR, Tonella RM, Damascena AS, Pereira CA, Caruso P. Interobserver agreement rate of the spontaneous breathing trial. $\mathrm{J}$ Crit Care 2013;28(1):62-68.

10. Jubran A, Tobin MJ. Pathophysiologic basis of acute respiratory distress in patients who fail a trial of weaning from mechanical ventilation. Am J Respir Crit Care Med 1997;155(3):906915. 